\title{
A CONSTELAÇÃO SISTÊMICA E OS MEIOS ALTERNATIVOS DE RESOLUÇÃO DE CONFLITOS
}

THE SYSTEMIC CONSTELLATION AND

ALTERNATIVE MEANS OF CONFLICT RESOLUTION

Nathália Silva e SANTOS ${ }^{1}$

ISSUE DOI: $10.21207 / 1983.4225 .631$

\section{RESUMO}

O presente artigo analisa as contribuições da técnica da constelação sistêmica, desenvolvida por Bert Hellinger, para a compreensão e solução de conflitos humanos no âmbito jurídico. A pesquisa tece considerações sobre os meios de autocomposição dos conflitos - consagrados pela Lei $n^{\circ} 13.140 / 2015$ e pelo Novo Código de Processo Civil - sobre o desenvolvimento da consciência humana, bem como observa o estabelecimento do Direito Sistêmico no ordenamento jurídico brasileiro. Outrossim, este estudo discorre sobre a relação entre os aspectos fenomenológicos, psicológicos e jurídicos na aplicação da constelação sistêmica no cerne dos meios alternativos de solução de conflitos. Por fim, examina alguns dados coletados sobre sobre da aplicação dessa técnica no Poder Judiciário.

Palavras-chave: Constelação sistêmica. Solução de Conflitos. Relações Humanas. Bert Hellinger.

\section{ABSTRACT}

The present article analyses the technical contributions of systemics constellation, developed by Bert Hellinger, for the comprehension and solution of human conflicts in the legal scope. The research has considerations about the means of self-composition of conflicts - enshrined in Law 13.140/2015 and the New Code of Civil Procedure - on the development of human consciousness, as well as observing the establishment of Systemics Law in the Brazilian legal system. Moreover, this study discusses about the relationship between phenomenological, psychological and legal aspects in the application of systemics constellation at the heart of alternative means of conflict resolution. Finally, it examines some data collected about the application of this technique in the Judiciary.

\footnotetext{
${ }^{1}$ Bacharel em Direito pela Universidade Federal Fluminense - UFF (2016). Advogada. Contato: nathaliasesantos@gmail.com. http://lattes.cnpq.br/4024115667444956.
} 
Keywords: Systemic Constellation. Conflict Resolution. Human Relationships. Berth Hellinger.

\section{INTRODUÇÃO}

O conflito é algo intrínseco à condição humana, está presente na constituição da sociedade desde os primórdios da evolução e surge da interação social. Nas civilizações mais primitivas e remotas os conflitos eram resolvidos por meio da lei do mais forte, a partir do advento do Código de Hamurabi as controvérsias passaram a ser solucionadas com base na proporcionalidade entre o ato praticado e a pena. Hodiernamente, o ordenamento jurídico é muito diferente desses pretéritos regramentos. O Direito está em constante modificação, na medida em que a sociedade se desenvolve, ele se aperfeiçoa.

No Brasil, a cultura da judicialização arraigou-se à sociedade, o que culminou no abarrotamento do Poder Judiciário. As maneiras de autocomposição da lide emergiram como forma de descongestionar a instituição judicial e estabeleceram um novo paradigma no universo jurídico. A mediação e a conciliação, que podem ser judiciais ou extrajudiciais, visam harmonizar as controvérsias, estimular a celeridade processual, e promover a desjudicialização.

Esses métodos de resolução de conflitos vêm ganhando cada vez mais destaque na legislação brasileira: com a Resolução n. 125/10 do Conselho Nacional de Justiça; em 2015 com a Lei 13.140/15, a qual instituiu o marco legal da mediação no Brasil; e em 2016 com a vigência do Novo Código de Processo Civil, que consagrou a primazia dos meios consensuais de solução de conflitos. O país está em um processo de transição, ou seja, está deixando a tradicional cultura da judicialização que enaltece os litígios para adotar a cultura preventiva.

Nesse sentido, o art. $3^{\circ}, \S 3^{\circ}$ do $\mathrm{CPC} / 15$, determina que os operadores do Direito devem estimular as práticas dos meios alternativos de solução de demandas e outros métodos, dentre os quais se pode inserir a constelação familiar. O Direito Sistêmico é um método sistêmico-fenomenológico de solução de conflitos, que está sendo desenvolvido com base nos ensinamentos Bert Hellinger, abrangendo a aplicação da abordagem hellingeriana no campo jurídico.

A técnica auxilia no entendimento e na harmonização dos distúrbios comportamentais e situações de conflitos, com a realização de uma 
análise fenomenológica do caso; esclarece o que gerou o confronto; favorece o desenvolvimento da empatia entre os participantes; e permite observar a consciência coletiva presente no caso constelado. Em outras palavras, a constelação sistêmica possibilita a compreensão de todo sistema que envolve o conflito e, a partir disso, busca propor soluções para sanar, de maneira duradoura, as causas que dão ensejo aos litígios.

Nesta pesquisa objetiva-se estudar a aplicação do método hellingeriano na esfera judicial, mais precisamente, na resolução de desavenças de cunho familiar. Posto que, os conflitos levados para uma sessão de constelação no ambiente jurídico, em regra, tratam sobre questões de origem familiar, tais como: alimentos, guarda de filhos, divórcios, alienação parental.

Com este ensaio não se busca enumerar todos os resultados que técnica pode gerar, mas sim, fazer um estudo demonstrativo e preliminar sobre a aplicação da técnica de constelação sistêmica no Judiciário, visando estimular e contribuir com os estudos acadêmicos sobre o Direito Sistêmico, tendo em vista a relevância e contemporaneidade da temática.

\section{BREVES REFLEXÕES SOBRE A CONSCIÊNCIA}

Na concepção da psicologia sócio-histórica, o homem é considerado um ser ativo, social e histórico, essa condição do ser humano reflete na constituição de suas maneiras de pensar, sentir e agir, ou seja, em sua consciência ${ }^{2}$. Essa definição muito se assemelha às reflexões sobre a consciência coletiva do sociólogo Émile Durkeim; às reflexões de Sigmund Freud sobre a psicologia das massas; e aos fundamentos da constelação sistêmica, também conhecida como constelação familiar.

A constelação familiar não pode ser perfeitamente compreendida, sem que se aborde a filosofia hellingeriana sobre a consciência. É evidente a necessidade de se analisar as consciências humanas para o melhor entendimento, uma vez que os níveis conscienciais influenciam diretamente nas relações sociais.

\footnotetext{
${ }^{2}$ FURTADO, Odair. In Psicologia sócio-histórica: uma perspectiva crítica em psicologia. Ana Mercês Bahia Bock, Maria da Graça Marchina Gonçalves, Odair Furtado (orgs.). São Paulo: Cortez, 2007, 3 ed. p. 81.
} 
Essa técnica permite identificar as causas, os vínculos, os eventos e os comportamentos dos indivíduos e dos grupos que originaram o conflito, a partir de representações aplicadas de acordo com a metodologia sistêmico-fenomenológica, o constelador consegue compreender todo o corpo social do sistema e, com isso, é capaz de oferecer caminhos para a solução do problema ${ }^{3}$.

De acordo com o estudo hellingeriano, o indivíduo é regido pela consciência individual e coletiva, a primeira o conduz pelos sentimentos da culpa e da inocência e pode ser caracterizada como boa ou má, enquanto a segunda se consiste nas regras, costumes, valores e crenças presentes no grupo em que o indivíduo está inserido. Logo, a consciência coletiva estabelece a coesão do grupo social, pois promove a harmonia e a organização das relações de trocas entre os membros do grupo ${ }^{4}$. Nas palavras do psicoterapeuta em estudo, "a consciência é, em primeiro lugar, um sentimento que nos ajuda a perceber como devemos agir para assegurar a nossa vinculação a um grupo importante para nós" 5 .

Segundo Hellinger, cada ser humano é regido por três espécies de consciências, quais sejam: consciência sistêmica ou coletiva, consciência individual ou pessoal e consciência suprema ou universal. A identificação das espécies de consciências é importante para entender os desequilíbrios tratados na constelação familiar, sobretudo a consciência coletiva.

A consciência sistêmica, também denominada como consciência coletiva, é responsável por reger o equilíbrio e definir os papéis de cada indivíduo no grupo, se manifesta em padrões comportamentais, em relacionamentos, nos estados de saúde, etc.

\footnotetext{
Muitos fenômenos anímicos que se manifestam nas constelações relacionam- se com os processos dessa consciência coletiva, que pode ser de um grupo, uma horda, um clã, uma estirpe ou uma família. Como geralmente não sentimos essa consciência, só podemos percebê-la em seus efeitos sobre os grupos. Na medida em que podemos percebê-la, isso nos dá a possibilidade de assumir conscientemente a condução, conseguindo boas soluções que satisfaçam a consciência grupal e simultaneamente ajudem a superar suas limitações ${ }^{6}$.
}

\footnotetext{
${ }^{3}$ SCHNEIDER, Jakob Robert. A prática das constelações familiares. Patos de Minas: Atman, 2007, 1 ed., p. 29.

${ }^{4}$ HELLINGER, Bert. Conflito e Paz: uma resposta. São Paulo: Cultrix, 2005, 1 ed., p. 23.

${ }^{5}$ Ibidem. p. 62.

${ }^{6}$ SCHNEIDER, Jakob Robert. Op. cit., p. 28.
} 
Nesse sentido, a consciência se caracteriza como um conhecimento inerente ou um saber instintivo, ligado às relações interpessoais. É o saber sobre o que é preciso para pertencer ao sistema; o saber relacionado com a sensação de dívida e; o saber sobre a própria contribuição para a ordem do grupo, para que possa funcionar como tall.

Tomando como base a análise feita por Freud em "Psicologia das massas a análise do eu", a psicologia individual e a grupal não podem ser absolutamente diferenciadas, porque a psicologia do individuo já é, em si mesma, uma função das relações entre uma pessoa e outra ${ }^{8}$. Esses dois ramos da psicologia são praticamente indissociáveis, porque no psiquismo particular, o "outro" é considerado enquanto referência, modelo, colaborador e rival, portanto, a psicologia individual é também, desde sua gênese, psicologia social ${ }^{9}$.

A abordagem freudiana sobre a psicologia das massas trata o ser humano como membro de um grupo social, uma tribo, um povo, uma instituição, uma classe, uma casta, ou como componente de uma aglomeração que se organiza como massa, em determinado momento, para atingir uma finalidade. Ocorre que a organização social constitui a "mente coletiva", consoante destaca Le Bon:

A peculiaridade mais notável apresentada por um grupo psicológico é a seguinte: sejam quem forem os indivíduos que o compõem, por semelhantes ou dessemelhantes que sejam seu modo de vida, suas ocupações, seu caráter ou sua inteligência, o fato de haverem sido transformados num grupo coloca- os na posse de uma espécie de mente coletiva que os faz sentir, pensar e agir de maneira muito diferente daquela pela qual cada membro dele, tomado individualmente, sentiria, pensaria e agiria, caso se encontrasse em estado de isolamento. Há certas idéias e sentimentos que não surgem ou que não se transformam em atos, exceto no caso de indivíduos que formam um grupo. O grupo psicológico é um ser provisório, formado por elementos heterogêneos que por um momento se combinam, exatamente como as células que constituem um corpo vivo, formam, por sua reunião, um novo ser que apresenta características muito diferentes daquelas possuídas por cada uma das células isoladamente $^{10}$. (grifos nossos)

\footnotetext{
${ }^{7}$ HELLINGER, Bert. Conflito e Paz: uma resposta. São Paulo: Cultrix, 2005, 1 ed. p. 62.

${ }^{8}$ FREUD, Sigmund. Psicologia das Massas e Análise do Eu e outros textos. Obras Completas Companhia das Letras - (1920-1923). Vol. 15. São Paulo: Companhia das Letras, 2011, p. 29.

${ }^{9}$ Ibidem, p. 10.

${ }^{10}$ LE BON apud FREUD, Sigmund. Op. cit., p. 13.
} 
Observa-se, que as colocações acima tratam o indivíduo sempre como um componente de um grupo. Regressando ao estudo da psicologia sócio-histórica, tem-se que a convivência em grupo promoveu o desenvolvimento da capacidade de união entre os seus componentes e a "retenção coletiva do conhecimento", desde o início da evolução humana, portanto, a consciência coletiva deriva-se da convivência em sociedade ${ }^{11}$.

A consciência coletiva também foi objeto de estudo do sociólogo Émile Durkheim:

$\mathrm{O}$ conjunto das crenças e dos sentimentos comuns à média dos membros de uma mesma sociedade forma um sistema determinado que tem vida própria; podemos chamá-lo de consciência coletiva ou comum. Sem dúvida, ela não tem por substrato um órgão único; ela é, por definição, difusa em toda a extensão da sociedade, mas tem, ainda assim, características específicas que fazem dela uma realidade distinta. De fato ela é independente das condições particulares em que os indivíduos se encontram: eles passam, ela permanece. (...) Ela é, pois, bem diferente das consciências particulares, conquanto só seja realizada nos indivíduos. Ela é o tipo psíquico da sociedade, tipo que tem suas propriedades, suas condições de existência, seu modo de desenvolvimento, do mesmo modo que os tipos individuais, muito embora de outra maneira ${ }^{12}$. (grifos nossos)

A visão do sociólogo deixa ainda mais evidente a semelhança entre as concepções sobre a consciência coletiva e os estudos desenvolvidos por Hellinger. Para Durkeim, o conjunto de crenças, costumes, valores do indivíduo, compõe um sistema que possui "vida própria". Essa perspectiva sistemática é abordada detalhadamente por Hellinger, para ele o sistema se caracteriza como um conjunto de elementos que se mantém unido ou vinculado em razão de interesses comuns ou de forças que os rodeiam.

A visão sistêmico-fenomenológica permite vislumbrar os conflitos sob novos ângulos, posto que é necessário transcender o conceito de consciência individual para adotá-la. Enquanto a consciência individual possui restrições em sua percepção e proporção, a consciência coletiva além de reger as relações interpessoais para a manutenção do grupo, também dá alicerces ao sistema. Desse modo, analisar todo o sistema é o melhor caminho para compreender os indivíduos e os conflitos, conforme a técnica da constelação familiar propõe.

\footnotetext{
${ }^{11}$ FURTADO, Odair. Op. cit, p. 81.

${ }^{12}$ DURKHEIM, Émile. Da divisão do trabalho social. Martins Fontes: São Paulo, 2010, p. 50.
} 
A consciência direciona o indivíduo ao encontro do que ele deve fazer para pertencer a um determinado grupo, e como deve se proteger para não ser punido ou excluído; bem como serve para avaliar as ações e os comportamentos individuais e/ou coletivos ${ }^{13}$. Hellinger destaca que existem forças atuantes na consciência de grupo, quais sejam: pertinência, hierarquia e equilíbrio.

Quando essas forças não são respeitadas, são criados os emaranhamentos. As consequências do desrespeito às ordens, os efeitos desse desrespeito são o surgimento de doenças, conflitos, sentimentos de infelicidade e, no caso da escola, as dificuldades e os transtornos de aprendizagem e de comportamento. As gerações seguintes (ou quem chega depois) passarão a reproduzir esses efeitos de forma inconsciente ${ }^{14}$.

De maneira geral, a consciência é entendida como um órgão psíquico que preza pelo equilíbrio das relações interpessoais, todavia esse conceito não é suficiente para compreendê-la. O ser humano é, inevitavelmente, um ser social, pois se encontra vinculado ou influenciado pelo grupo social a que pertence. Na convivência social, o indivíduo adquire crenças, valores, costumes, capazes de influenciar no desenvolvimento da consciência tanto pessoal quanto coletiva. Portanto, para a melhor compreensão das relações humanas, do indivíduo e dos conflitos, é imprescindível que se pesquise o desenvolvimento consciencial do ser humano como um todo - o indivíduo, seu contexto e suas relações interpessoais - é isso que técnica da constelação familiar permite observar.

Levando as considerações supracitadas ao cerne familiar, de acordo com a concepção sistêmica hellingeriana, a família é envolvida por uma "alma familiar" - uma espécie de consciência coletiva familiar - capaz de unir os membros da família ente si, de forma que o destino de um influencie na vida de outros membros e seja transmitido de geração em geração ${ }^{15}$. A transferência geracional de transtornos familiares, nada mais é do

\footnotetext{
${ }^{13}$ SCHNEIDER, Jakob Robert. Op. cit., p. 27.

${ }^{14}$ BRAGA, Ana Lucia de Abreu. Psicopedagogia e Constelação familiar: um estudo de caso. Revista Psicopedagogia: Ribeirão Preto, 2009, p. 278. Disponível em: 〈https://goo.gl/JiJ12d〉. Acessado em: 25/01/2018.

${ }^{15}$ STORCH, Sami. Direito sistêmico: a resolução de conflitos por meio da abordagem sistêmica fenomenológica das constelações familiares. Revista Entre aspas: revista da Unicorp / Tribunal de Justiça do Estado da Bahia - ano.1, n.1, (abr.2011) - Salvador: Universidade Corporativa do TJBA, 2011- Catalogação do volume 5, publicado em Julho de 2016, p. 307.
} 
que uma herança afetiva, que engendra uma sequência de destinos trági$\cos ^{16}$.

\section{A CONSTELAÇÃO SISTÊMICA}

Bert Hellinger nasceu em 1925, é psicoterapeuta, teólogo, filósofo e psicanalista alemão. Por meio da abordagem fenomenológica, o estudioso criou a técnica da constelação familiar, com o propósito de compreender, por completo, os desequilíbrios existentes nas relações humanas. Hellinger ganhou papel de destaque na esfera profissional e hoje é visto como um dos terapeutas-chave da psicoterapia atual, sua teoria se propaga pelo mundo, as constelações familares estão sendo usadas não só no seio familiar, como também em empresas e no judiciário, pois se percebeu que as leis sistêmicas atuam em todos os sistemas e não se restringem ao apenas no contexto familiar ${ }^{17}$.

A constelação sistêmica possui o propósito de promover a análise dos padrões comportamentais de grupos familiares, grupos de trabalho, dentre outros. Essa técnica psicoterapêutica funciona, predominantemente, pelo viés da dinâmica de grupo, na qual se busca considerar o papel de cada membro do grupo no sistema e sua relação interpessoal, mas também podem ser utilizados bonecos ou outros objetos para representar os componentes do sistema. Na dinâmica grupal, os participantes se dispõem a representar membros do sistema do constelado sob a condução do facilitador (constelador), durante a sessão os participantes percebem sensações e movimentos das forças ocultas que regem o sistema.

De acordo com a teoria sistêmica, existem dinâmicas e forças ocultas, que influenciam no comportamento dos indivíduos quando estão introduzidos em um conjunto ${ }^{18}$. Nesse contexto, a constelação familiar busca desnudar o que está oculto no sistema para "curar" a causa dos conflitos.

\footnotetext{
${ }^{16}$ BRAGA, Ana Lucia de Abreu. Op. cit., p. 276.

${ }^{17}$ CHIQUETTI, Taciana; CRUZ, Carlos Henrique Souza da. Psicologia Jurídica e Direito de Família: para além da perícia psicológica. Manaus: UEA Edições, 2017, p. 277.

${ }^{18}$ DIAS, Cristiana Kaipper. As contribuições da teoria sistêmica de Bert Hellinger para a compreensão das relações humanas e resolução de conflitos. Revista Eletrônica da Fainor, Vitória da Conquista, v.7, n.1, jan./jun. 2014, p.10. Disponível em: 〈https://goo.gl/a6DPwA〉. Acessado em: 24/01/18.
} 
O método de Hellinger, busca identificar a causa que desencadeou os conflitos dentro de determinado sistema e investigar maneiras para reequilibrá-lo. Durante a sessão de constelação, o constelador volta seu olhar para os emaranhamentos que rodeiam os conflitos, observa a teia relacional que os desequilíbrios se inserem. O facilitador examina a composição do campo, de maneira fenomenológica, o que permite a compreensão de questões que não são percebidas se não forem observadas de forma sistemática.

O constelado indica uma questão para ser trabalhada, escolhe pessoas para representar os "personagens" do seu campo relacional e os posiciona conforme sua intuição determina:

A aplicação do trabalho consiste em que, nós, como clientes numa Constelação, sejamos solicitados pelo facilitador o mínimo possível a respeito de informações a nosso respeito e a respeito do tema que queremos trabalhar. $\mathrm{O}$ facilitador pede apenas que digamos o que queremos. Em seguida somos convidados pelo facilitador a escolher, aleatoriamente, entre pessoas (de um grupo), ou figuras (quando do trabalho individual), ou desenhos, algo ou alguém que possa representar a questão por nós colocada e posicioná-los no espaço seguindo nossos sentimentos ou percepção interna ${ }^{19}$.

Observa-se, portanto, que na teoria sistêmica, os grupos são controlados por forças que interferem no comportamento de seus membros e consistem na própria consciência coletiva. $\mathrm{O}$ processo de constelação familiar permite a identificação e manifestação dessa consciência, com isso, se torna possível verificar os emaranhados sistêmicos do constelado e solucionar os desequilíbrios existentes. Por derradeiro, a técnica, através de sua abordagem fenomenológica, destaca a relevância das relações interpessoais, uma vez que demonstra que os seres humanos sempre estão inseridos nos contextos de grupo.

\section{OS MEIOS ALTERNATIVOS DE RESOLUÇÃO CONFLITOS E A BUSCA PELA HUMANIZAÇÃO DO DIREITO}

Os meios alternativos de resolução de conflitos possuem o intuito de descongestionar a instituição judicial, que se apresenta demasiadamente

${ }^{19}$ CARMO, Maria Scarlet do. Uma breve apresentação sobre a constelação sistêmica fenomenológica. Editora Atlas, 2015, 1 ed., p. 13. 
onerosa e morosa, bem como o poder de mobilizar todos os atores envolvidos na lide para pacificar a perturbação social. Ademais, pretendem dar tratamento mais satisfatório aos conflitos de interesses emergentes na sociedade.

A conciliação e a mediação são métodos alternativos de resolução de conflitos, que vêm se fortalecendo e ganhando espaço nos ordenamentos jurídicos modernos. A "cultura da sentença", caracterizada pela excessiva judicialização das controvérsias, tem sido substituída pela propagação da "cultura da pacificação", a qual valoriza a prevenção dos conflitos e a solução amigável estabelecida pelos próprios conflitantes ${ }^{20}$.

No trâmite do projeto do novo Código de Processo Civil, os legisladores se mostraram preocupados com o crescente clamor social pela a humanização do Direito, tendo em vista a dificuldade do acesso à justiça e o acúmulo de processos judiciais no país. Por essa razão, foram elaboradas normas para incentivar a resolução harmônica das controvérsias. O CPC/15 atribuiu grande importância aos meios alternativos de solução de conflitos, ao incluir os conciliadores e os mediadores como auxiliares da justiça (art. 148 , II) e ao estabelecer a necessidade de criação de centros judiciários especializados na solução consensual de conflitos pelos tribunais (arts. 165 a 175).

Segundo Humberto Theodoro Júnior ${ }^{21}$, atualmente, o objetivo maior do Judiciário é dar solução justa às demandas, aproximar os litigantes da harmonia e da justiça, com o intuito de reduzir os atritos sociais e promover a pacificação social. Nas palavras de Roger Perrot, "o jurisdicionado aspira a uma justiça mais simples, menos solene, mais próxima de suas preocupações quotidianas, àquilo que numa palavra se denomina justiça de proximidade" 22.

Imperioso notar que, para se instituir a humanização processual, é preciso que o magistrado priorize a efetivação da justiça durante toda a tramitação do feito, mas não só no momento da sentença ${ }^{23}$. Nesse sentido, o Código de Processo Civil de 2015, enalteceu a política procedimental que

\footnotetext{
${ }^{20}$ WATANABE, Kazuo. Política judiciária nacional de tratamento adequado dos conflitos de interesses: utilização dos meios de resolução de controvérsias. In: MENDES, Aluísio Gonçalves de Castro; WAMBIER, Teresa Arruda Alvim (org.). O processo em perspectiva: jornadas brasileiras de direito processual. São Paulo: RT, 2013, p. 243.

${ }^{21}$ THEODORO JÚNIOR, Humberto. Curso de Direito Processual Civil - Teoria geral do direito processual civil, processo de conhecimento e procedimento comum. vol 1 . 58. ed. rev., atual. e ampl. - Rio de Janeiro: Forense, 2017, p. 19.

${ }^{22}$ PERROT, Roger. apud THEODORO JÚNIOR, Humberto. Op. cit., p. 21.

${ }^{23}$ Ibidem, p. 79.
} 
favorece humanização das ações durante todos os momentos processuais, nos seguintes dispositivos: o art. $3^{\circ}, \S \S 2^{\circ}$ e $3^{\circ}$, por exemplo, estimulou a autocomposição da lide; o art. 139,VIII conferiu poderes ao juiz para, a qualquer tempo, convocar as partes a prestar esclarecimentos pessoais sobre os fatos que deram ensejo à causa (art.139,VIII); e no art. 334 existe a previsão da realização de uma audiência prévia de conciliação e mediação como etapa obrigatória, anterior à formação da lide, como regra geral para todos os processos cíveis; dentre outros.

Os meios alternativos de resolução de conflitos são as formas de solução consensuais que garantem ao Judiciário uma celeridade, e a consequente diminuição no número de processos judiciais. Embora o CPC/15 tenha incentivado a desjudicialização, os instrumentos de origem autenticamente jurídica não têm sido suficientes para resolver, de modo definitivo, as demandas judiciais.

\subsection{A APLICAÇÃO DA CONSTELAÇÃO FAMILIAR NO JUDICIÁRIO}

A expressão "Direito Sistêmico" foi adotada pelo magistrado Sami Storch para caracterizar o uso do método sistêmico-fenomenológico como meio alternativo de solução de conflitos no Judiciário. O Direito Sistêmico é aplicado de modo hermenêutico, valorizando todos os emaranhados presentes no sistema e resulta de uma síntese da experiência humana em vários domínios. De acordo com as concepções de Amilton Rosa e Sami Storch só é possível solucionar os conflitos quando se promove o equilíbrio e a paz em todo o sistema, pois o desequilíbrio de um membro do "todo" reflete nos outros ${ }^{24}$.

Storch foi pioneiro mundial na instauração da técnica hellingeriana na esfera judicial, ele começou a utilizá-la na Comarca do município de Amargosa, interior da Bahia. Desde o início do uso do método, em ações de família (divórcio, guarda, alimentos), o magistrado, segundo dados do

\footnotetext{
${ }^{24}$ ROSA. Amilton Plácido da. Direito sistêmico: a justiça curativa, de soluções profundas e duradouras. In: Revista MP Especial, ano 2, ed. 11, janeiro de 2014, Ministério Público do Mato Grosso do Sul, p. 53. Disponível em: 〈https://goo.gl/8ueTgK〉. Acessado em: 30/01/2018.
} 
CNJ de $2015^{25}$, conseguiu homologar até $100 \%$ de acordos com o uso da constelação familiar antes das audiências de conciliação ou mediação.

Ao levar em consideração os aspectos sistêmico-fenomenológicos das lides, o magistrado deve atuar em prol da realização de um acordo efetivo entre as partes, que seja capaz de harmonizar a relação. A abordagem sistêmica é capaz de instaurar uma nova forma de "pensar" o Direito e permitir o "olhar" mais humanizado e sensível sobre as questões jurídicas, bem como o tratamento mais aprofundado do conflito. A técnica da constelação familiar, aplicada no Poder Judiciário, se esforça para apaziguar os embates emocionais, os quais costumam ser o fomento de diversos litígios.

O direito sistêmico é a tradução de um direito sensível, humanizado, inclusivo, que se sustenta na autonomia da vontade, na dignidade da pessoa, valendo-se de ações e intervenções sistêmicas que conduzam à responsabilização individual e reflexiva por meio de uma experiência pessoal de enfrentamento da realidade (verdade) imperceptível, que movimenta as relações humanas e por consequência atinge as relações processuais e o todo o sistema judiciário ${ }^{26}$.

A teoria sistêmica de Hellinger, quando incorporada ao meio jurídico, potencializa a resolução de conflitos, pois propicia que os indivíduos entrem em contato com as raízes da controvérsia e se abram para compreender o problema sob nova perspectiva.

A resolução no 125/10 do CNJ, a Lei de Mediação e o Código de Processo Civil de 2015 concretizaram a mudança de paradigma da cultura jurídica nacional.

Em 2010, o Conselho Nacional de Justiça (CNJ) editou a Resolução $n^{\circ} 125 / 2010$, que instituiu a Política Judiciária Nacional de tratamento adequado aos problemas jurídicos e aos conflitos de interesses - visando disseminar a cultura da pacificação social - e reconheceu os meios não adversariais de solução de conflitos como instrumentos efetivos de harmonização social, solução e prevenção de litígios.

\footnotetext{
25 Segundo notícia veiculada pelo CNJ. Disponível em: 〈https://goo.gl/PGff1A $\rangle$. Acesso em: 28/01/18.

${ }^{26}$ LACERDA, Sttela Maris Nerone. Direito sistêmico e direitos humanos: a aplicação das constelações familiars para tratamento dos conflitos judiciais. In: II Simpósio Internacional Interdisciplinar em Ciências Sociais Aplicadas. Anais. Ponta Grossa: UEPG, 2017. Disponível em: <https://goo.gl/WBJsMD>. Acessado em: 30/01/2018.
} 
No que tange ao processo civil, o art. $3^{\circ}, \S 3^{\circ}$ do $\mathrm{CPC} / 15$, determina que os operadores do Direito devem estimular as práticas de conciliação, mediação e outros métodos de solução consensual de conflitos. Outrossim, reitera-se que a autocomposição de conflitos ganhou tanta importância no novo ordenamento processual civil que o art. 694, da referida Lei, determina que "nas ações de família todos os esforços serão empreendidos para a solução consensual da controvérsia, devendo o juiz dispor do auxílio de profissionais de outras áreas de conhecimento para a mediação e conciliação".

Ademais, o artigo 359 do Código prevê que, instaurada a audiência, "o juiz tentará conciliar as partes, independentemente do emprego anterior de outros métodos de solução consensual de conflitos, como a mediação e a arbitragem". Ou seja, a constelação pode ser aplicada nos processos judiciais, a critério dos magistrados, em momento oportuno, de preferência, antes da audiência de conciliação ou mediação.

Por conseguinte, a técnica psicoterapêutica da constelação familiar está em consonância com esses dispositivos, visto que o rol dos métodos de solução de conflitos não é taxativo. Desse modo, compreende-se que a prática se insere nesse contexto, como meio alternativo possível de ser aplicado no âmbito judicial.

As leis sistêmicas, ao serem utilizadas no Poder Judiciário, não possuem o escopo de substituírem a conciliação e a mediação, mas sim de sensibilizar as partes para facilitar a realização de acordos e restabelecer o diálogo. Geralmente as sessões são realizadas antes das audiências de conciliação. Diante dos índices elevados de acordo ${ }^{27}$, impulsionados pelo uso da técnica hellingeriana, embora não haja nenhuma legislação que trate especificamente deste método, ele está se disseminando rapidamente no território nacional, o TJDFT, por exemplo, possui um projeto para o desenvolvimento dessa prática, assim como existem vários cursos de extensão e de especialização sobre o tema se propagando pelo Brasil.

No âmbito nacional, o Conselho Nacional de Justiça, em outubro de 2016, estimou que pelo menos 11 estados (Goiás, São Paulo, Rondônia,

\footnotetext{
${ }^{27}$ Os dados relativos ao uso da constelação familiar na esfera judicial, ainda são baseados em estudos preliminares devido à contemporaneidade da matéria e a existência de poucos trabalhos acadêmicos sobre o assunto. Os índices de acordo observados na comarca da Amargosa - BA foram tão elevados que geraram curiosidade nos operadores do direito e acabaram impulsionando a disseminação da técnica pelo país. No entanto, faz-se necessário um estudo mais detalhado para ser possível constatar se a aplicação da constelação familiar é vantajosa ou não para os litigantes. Esses dados serão observados no decorrer deste artigo.
} 
Bahia, Mato Grosso, Mato Grosso do Sul, Pará, Paraná, Rio Grande do Sul, Alagoas e Amapá) e o Distrito Federal já utilizam "a dinâmica da 'Constelação Familiar’ para ajudar a solucionar conflitos na Justiça brasileira” ${ }^{28}$.

Enquanto método sistêmico-fenomenológico de solução de conflitos, a constelação familiar, se propõe a atuar na origem do problema e identificar os emaranhados do sistema que circundam o litígio. Busca, portanto, compreender a consciência coletiva que rege o sistema e que os litigantes pertencem, identificar as dificuldades da ação e, assim, solucionar o conflito da maneira duradoura.

\subsubsection{LITÍGIOS FAMILIARES E O USO DA CONSTELÇÃO SISTÊMICA}

O emprego dessa técnica, como meio alternativo de resolução de conflitos, encontra campo favorável nas varas de família, pois os litígios costumam apresentar problemáticas complexas diretamente vinculadas às questões emocionais. Porém, a tendência é que essa prática se alastre para outros ramos de ações judiciais.

A atuação dos juízes não pode se limitar a aplicação da "fria" da lei, mas sim buscar o equilíbrio entre a formalidade e a liberdade de interpretação das normas. Com isso, é recomendável que suas decisões se aproximem ao máximo da justiça ideal. Segundo Piero Calamandrei, não é suficiente que os magistrados conheçam com perfeição as leis tais como são escritas; mas é imprescindível que conhecessem igualmente a sociedade em que essas leis devem vigorar ${ }^{29}$.

Na realidade das varas de família, a sensibilidade dos operadores do Direito necessita ser ainda maior, posto que as ações tratam de assuntos delicados que costumam ser permeadas por sentimentos que desestabilizam os litigantes. Storch alerta para o fato de que em lides familiares, a tradicional instrução processual tende a provocar o agravamento do conflito e o distanciamento entre as partes ${ }^{30}$.

\footnotetext{
${ }^{28}$ Segundo notícia veiculada pelo portal do CNJ. Disponível em: 〈https://goo.gl/TRKFhn〉. Acessado em: 28/01/18.

${ }^{29}$ CALAMANDREI, Piero. Eles, os juízes, vistos por um advogado. São Paulo: Martins Fontes, 1995, 1 ed., p. 183.

${ }^{30}$ STORCH, Sami.Op. cit., p. 306.
} 
Tal fenômeno é ainda mais claramente visível nos conflitos de ordem familiar, que têm origem quase sempre numa história de amor (um casamento ou caso amoroso) e geralmente envolve filhos de ambas as partes. A instrução processual, nesses casos, é altamente nociva para todos os envolvidos, pois cada testemunha que depõe a favor de uma parte pode trazer à tona fatos comprometedores relativos à outra, alimentando o rancor e o ressentimento e dificultando a obtenção da paz. Assim, mesmo depois de concluída a instrução processual, julgada a ação, esgotados os recursos e efetivada a sentença, o conflito permanece. Em muitos casos, outras ações judiciais são propostas para discutir e rediscutir os mesmos assuntos e outros subjacentes à mesma relação ${ }^{31}$.

Vale destacar que a realização de acordos pelos meios tradicionais de resolução de conflitos, muitas vezes não basta para sanar, definitivamente, o processo. Nota-se que o legislador percebeu esse fato, quando da edição do Código de Processo Civil de 2015, uma vez que enalteceu a participação de profissionais de diferentes áreas de atuação para que as normas processuais ganhem contornos humanizados (vide art. 694).

Os juízes de Família buscam a realização de acordos, o que, embora muitas vezes seja conseguido, nem sempre produz efeitos concretos, no sentido amplo, uma vez que, sem a minimização dos conflitos emocionais subjacentes, os conflitos jurídicos tendem a reanimar-se (...). O Judiciário, no entanto, na interface psicojurídica, pode ser um lócus apropriado como intermediário da utilização de modernos recursos de ajuda psicológica, viabilizados por meio de práticas sistêmicas conduzidas dentro da visão sistêmico-construtivista $^{32}$. (grifos nossos)

Porém, mecanismos interdisciplinares, tais como a constelação familiar, podem auxiliar na efetivação da justiça e da paz social.

\subsection{DADOS ESTATÍSTICOS}

A utilização da constelação sistêmica no âmbito judicial é relativamente nova, começou a ser implantada pelo juiz Sami Storch em 2004 e sua expansão pelos tribunais do país ainda é muito recente, o que dificulta a coleta de dados científicos sobre sua aplicação. A análise estatística está em fase inicial, ainda dotada de informalidade, apesar de ter começado a

\footnotetext{
${ }^{31}$ Ibidem.

${ }^{32}$ CEZAR FERREIRA, Verônica A. da Motta. Família, separação e mediação: uma visão psicojurídica. São Paulo: Editora Método, 2004, p. 55.
} 
ser discutida, lentamente, no seio acadêmico. Não existe doutrina e tampouco legislação específica que trate da constelação familiar. Em virtude disso, o estudo dessa prática no âmbito jurídico carece de dados substanciais para se constatar, de maneira precisa, sua eficácia.

O Tribunal de Justiça do Distrito Federal e dos Territórios (TJDFT) adotou o "Projeto Constelar e Conciliar", na Vara Cível, de Família, Órfãos e Sucessões do Núcleo Bandeirante, do Distrito Federal, em menos de um ano de realização das vivências da técnica sistêmica, o índice de acordos alcançados, em 2016, foi de $75 \%$, considerando aqueles processos em que ambas as partes participaram:

\begin{tabular}{|c|c|c|c|c|}
\hline $\begin{array}{l}\text { Projeto Constelar e Conciliar - vCFOS } \\
\text { Núcleo Bandeirante }\end{array}$ & $18 / 03 / 2016$ & $20 / 05 / 2016$ & $17 / 06 / 2016$ & $01 / 07 / 2016$ \\
\hline Tema Selecionado & guarda & divórcio litigioso & $\begin{array}{l}\text { inventário e } \\
\text { alimentos }\end{array}$ & guarda \\
\hline $\mathrm{n}^{\circ}$ de processos convidados & 136 & 19 & 15 & 11 \\
\hline$n^{\circ}$ processos presentes no evento & 20 & 13 & 6 & 9 \\
\hline$n^{\circ}$ processos com ambas partes presentes & 1 & 7 & 0 & 2 \\
\hline \\
\hline Audiênncias marcadas & 14 & 13 & 6 & 9 \\
\hline ACORDOS & 4 & 7 & 2 & 7 \\
\hline $\begin{array}{r}\text { acordos em processos com ambas as partes persentes no } \\
\text { sia do evento }\end{array}$ & o & 5 & 0 & 2 \\
\hline & & & & \\
\hline \multicolumn{5}{|l|}{ RESULTADOS: } \\
\hline ADESĀOAO PROJETO & $15 \%$ & $68 \%$ & $40 \%$ & $82 \%$ \\
\hline ACORDOS & $20 \%$ & $54 \%$ & $33 \%$ & $78 \%$ \\
\hline ACORDO (ambas partes presentes no evento) & não se aplica & $71 \%$ & não se aplica & $100 \%$ \\
\hline Satisfaçāo das partes com o projeto & $89 \%$ & $70 \%$ & $83 \%$ & $100 \%$ \\
\hline Observaçbes & $\begin{array}{l}\text { Motivo da baja adesaloc } \\
\text { emviado simples comvite }\end{array}$ & & $\begin{array}{l}\text { Motivo baika adestas: } \\
\text { herdeiros dos immentatios }\end{array}$ & \\
\hline
\end{tabular}

\begin{tabular}{|c|c|c|c|c|c|c|c|c|}
\hline $26 / 08 / 2016$ & $23 / 09 / 2016$ & $21 / 10 / 2016$ & $18 / 11 / 2016$ & $31 / 03 / 2017$ & $26 / 05 / 2017$ & $28 / 07 / 2017$ & $29 / 09 / 2017$ & $10 / 11 / 2017$ \\
\hline $\begin{array}{l}\text { Divórcio e } \\
\text { União Estável }\end{array}$ & Guarda & $\begin{array}{c}\text { Busca e apreensão de } \\
\text { menores }\end{array}$ & $\begin{array}{c}\text { Divórcio e Uniäo } \\
\text { Estável c/c alimentos }\end{array}$ & Guarda & Alimentos & Alimentos & $\begin{array}{c}\text { Divórcio e União } \\
\text { estável }\end{array}$ & Guarda \\
\hline 4 & 8 & 7 & 10 & 9 & 13 & 16 & 15 & 15 \\
\hline 4 & 4 & 5 & 7 & 6 & 11 & 13 & 12 & 11 \\
\hline 0 & 3 & 2 & 4 & 2 & 3 & 4 & 7 & 6 \\
\hline & & & & & & & & \\
\hline 4 & 4 & 5 & 7 & 6 & 11 & 13 & 11 & 11 \\
\hline 3 & 1 & 4 & 5 & 4 & 8 & 8 & 5 & 8 \\
\hline 0 & 1 & 1 & 4. & 2 & 3 & 3 & 4 & 4 \\
\hline & & & & & & & & \\
\hline $100 \%$ & $50 \%$ & $71 \%$ & $70 \%$ & $67 \%$ & $85 \%$ & $81 \%$ & $80 \%$ & $73 \%$ \\
\hline $75 \%$ & $25 \%$ & $80 \%$ & $71 \%$ & $67 \%$ & $73 \%$ & $62 \%$ & $42 \%$ & $73 \%$ \\
\hline nẵo se aplica & $33 \%$ & $50 \%$ & $100 \%$ & $100 \%$ & $100 \%$ & $75 \%$ & $57 \%$ & $67 \%$ \\
\hline $75 \%$ & $92 \%$ & $82 \%$ & $91 \%$ & $82 \%$ & $87 \%$ & $80 \%$ & $85 \%$ & $83 \%$ \\
\hline $\begin{array}{l}\text { "Feito acordo em outro } \\
\text { processo com as mesmas } \\
\text { partes (didudecio e rec. }\end{array}$ & & Fetto acordo posterior na All & \begin{tabular}{|c|} 
"Feito acordo em outro \\
processo com as mesmas \\
partes (execouclo allimentios)
\end{tabular} & & & $\begin{array}{c}\text { Feto acordc posterior } \\
\text { na } \mathrm{AU} \\
\end{array}$ & & \\
\hline
\end{tabular}

\begin{tabular}{|l|lr|}
\hline ADESĀO MÉDIA fcom imtim & $\mathbf{7 2 \%}$ \\
\hline MÉDIA DE ACORDOS & $\mathbf{5 8 \%}$ \\
\hline COM AMBAS PARTES & $\mathbf{7 5 \%}$ \\
\hline Número de acordos & & $\mathbf{5 5}$ \\
\hline
\end{tabular}

Fonte: TJDFT (2017) ${ }^{33}$

\footnotetext{
${ }^{33}$ Tabela retirada do Tribunal de Justiça do Distrito Federal e Territórios - Diagnóstico geral do projeto dados (2017). Disponível em: 〈https://goo.gl/71HqCX〉. Acessado em: 30/01/2018.
} 
O magistrado André Tredinnick, titular da $1^{\text {a }}$ Vara de Família do Foro Regional da Leopoldina (TJRJ), idealizou o Projeto Constelações, com o intuito de instituir a técnica da constelação familiar como meio alternativo de solução de conflitos. Em 2016, foram selecionados cerca de 300 processos semelhantes, que discutiam a guarda de filhos, pensão alimentícia, divórcio, etc. Os litigantes eram convidados a participar de oficinas de constelação e depois de um lapso temporal seus casos eram direcionados para a realização de audiências de mediação e conciliação. Ao final dos encontros, os participantes respondiam a um questionário para avaliar o método. Os resultados preliminares da pesquisa constataram $86 \%$ das audiências realizadas após a constelação resultaram em acordos e que $80 \%$ dos participantes aprovaram o uso do método ${ }^{34}$.

No artigo "Direito sistêmico: a resolução de conflitos por meio da abordagem sistêmica fenomenológica das constelações familiares", Storch promoveu uma análise sobre sua experiência com a técnica e revelou alguns resultados do uso:

\begin{abstract}
ANÁLISE ESTATÍSTICA (VARA DE FAMÍLIA): nas audiências efetivamente realizadas com a presença de ambas as partes, o índice de acordos foi de $100 \%$ nos processos em que ambas participaram da vivência de constelações; $93 \%$ nos processos em que uma delas participou; e $80 \%$ nos demais; nos casos em que ambas as partes participaram da vivência, $100 \%$ das audiências se efetivaram, todas com acordo; nos casos em que pelo menos uma das partes participou, $73 \%$ das audiências se efetivaram e $70 \%$ resultaram em acordo; nos casos em que nenhuma das partes participou, $61 \%$ das audiências se efetivaram e $48 \%$ resultaram em acordo ${ }^{35}$.
\end{abstract}

Diante desses dados, embora haja grande entusiasmo com a aplicação da constelação familiar no Judiciário, ainda não é possível dimensionar, na seara científico-acadêmica, o êxito de seu uso como meio alternativo de solução de conflitos.

\footnotetext{
${ }^{34}$ Dados coletados pelo Núcleo Permanente de Métodos Consensuais de Solução de Conflitos (Nupemec). Disponível em: 〈https://goo.gl/cJxoS6>. Acessado em: 30/01/2018.

${ }^{35}$ STORCH, Sami. Op. cit., p. 310.
} 


\title{
$5 \quad$ PONTOS CONTROVERTIDOS
}

A utilização da constelação familiar no ambiente jurídico é inovadora. Embora alguns magistrados tenham notado aumentos significativos na homologação de acordos com o uso desse método, em especial, nas varas de família, seu estudo carece de pesquisa mais aprofundada e caráter científico. A ausência de trabalhos, com relevância significativa, sobre a matéria, dá margem à desconfiança, tanto da parte dos operadores do Direito quanto da sociedade em geral.

Destaca-se que não é objetivo deste artigo prolongar-se na discussão sobre as controvérsias na utilização da técnica, mas sim analisar a constelação familiar no âmbito fenomenológico, psicológico e sua relação com os meios alternativos de resolução de conflitos. Porém, por esmero, a partir deste momento, serão apresentadas algumas impressões lacônicas sobre as polêmicas que envolvem o método hellingeriano no cerne jurídico.

Diversos tipos de problemáticas podem ser objeto de uma constelação sistêmica, no entando, quando essa técnica é aplicada no Poder Judiciário, faz-se necessário que a atuação seja focal:

\begin{abstract}
Como a Constelação trabalha com a solução, limitou-se trabalhar o ponto "essencial" do conflito, àquele que motivara o pleito judicial. Aliás, "essencial" é uma palavra-chave para Hellinger, situando-a como referencial básico na condução de sua técnica; cerne orientador para se intervir no campo sistêmico de alguém. Ponto de largada e, ao mesmo tempo, ponto de chegada a partir do qual um constelador direciona seu trabalho. Há que haver, ainda, um esvaziamento interior, não julgamento e ausência de intencionalidade ${ }^{36}$.
\end{abstract}

Muitas vezes, a cadeia sistêmica das partes é muito densa e possui diversos emaranhamentos, não se restringindo apenas àquele ponto "essencial" determinado pelo operador do Direito, o que dificulta a resolução efetiva do conflito.

Outro ponto diz respeito à laicidade estatal. O Brasil é oficialmente um Estado laico (art. $5^{\circ}$, VI da CRFB/88), mas há uma grande desconfiança quanto à laicidade do método hellingeriano. Entretanto, os estudiosos sobre o assunto defendem que a técnica não possui qualquer conotação religiosa ${ }^{37}$.

\footnotetext{
${ }^{36}$ Ibidem. p. 289.

37 Idem, entrevista cedida ao Programa Fantástico em 14/05/2017. Disponível em: <https://goo.gl/K2ww44>. Acessado em: 30/01/2018.
} 
A questão mais controversa diz respeito à aplicação da constelação sistêmica na esfera criminal, mais precisamente, nos casos de violência doméstica contra a mulher. Em virtude dos resultados preliminares sobre o uso da técnica psicoterapêutica serem positivos, existem muitos projetos em tribunais brasileiros, que visam ampliar seu uso para além das varas de família, inclusive nas varas especializadas de violência doméstica e familiar contra mulher.

As dificuldades de efetivação da Lei Maria da Penha "têm evidenciado as resistências e limites do sistema de justiça em garantir uma prestação jurisdicional adequada nos casos envolvendo violência de gênero" ${ }^{38}$. Mesmo com o marco legislativo dessa lei, as mulheres continuam sofrendo discriminação e não possuem garantia alguma de que seus direitos serão respeitados. Isso leva a questionar se o método hellingeriano seria adequado para tratar a violência contra a mulher na esfera jurídica. No Poder Judiciário a técnica poderia representar mais um obstáculo à efetivação dos direitos humanos das mulheres, podendo, por exemplo, retardar o deferimento das tutelas protetivas de urgência.

\section{CONSIDERAÇÕES FINAIS}

O ordenamento jurídico brasileiro está em transição do modelo litigioso para o modelo preventivo de solução consensual das demandas. Os meios alternativos de solução de conflitos surgiram em virtude da sobrecarga de processos no Poder Judiciário, com o objetivo de descongestioná-lo. Com a entrada em vigor do novo Código de Processo Civil, o uso de meios que facilitem e estimulem a resolução consensual das demandas ganhou grande incentivo, pois além de promoverem o descongestionamento judicial, possibilitam o acesso à justiça.

Não se pode olvidar que o Judiciário desempenha um trabalho social emblemático, contudo as formações dos advogados, magistrados, promotores, etc, não os preparam para lidar com questões de cunho emocional. O olhar do operador do Direito, em regra, é engessado à análise pura e fria da legislação, o que representa um grande óbice à prestação jurisdicional satisfativa.

\footnotetext{
${ }^{38}$ SEVERI, Fabiana Cristina. O gênero da justiça e a problemática da efetivação dos direitos humanos das mulheres. Revista Direito e Práxis. v. 7, 2016, p. 82. Disponível em: <https://goo.gl/fMWhTh>. Acessado em: 25/10/2017.
} 
O juiz aprendeu na faculdade o que é a briga, o que é confronto, o que é processo. Ele não foi treinado para conciliar, mediar, para restabelecer o diálogo entre as partes, para entender o que as pessoas sentem, para permitir que as pessoas manifestem suas emoções, seus sentimentos e angústias ${ }^{39}$.

Em virtude da complexidade das relações humanas, os operadores do Direito devem encarar os litígios por um viés mais humanizado e é isso que a constelação sistêmica pretende viabilizar. Por meio da intersecção entre aspectos ligados à Psicologia e ao Direito, as questões emocionais são tratadas como componentes do conflito, elementos decisivos para sua solução e prevenção. A adoção dessa visão interdisciplinar torna o sistema judicial mais próximo do ideário de justiça.

O homem é um ser social, conforme foi demonstrado pelas concepções: psicologia sócio-histórica; da psicologia das massas freudiana; da consciência coletiva de Durkeim; da constelação familiar. Os conceitos apresentados possuem muitas semelhanças e todos apontam para a necessidade de uma análise sistemática, ou seja, a necessidade de ir além do indivíduo para se compreender as relações interpessoais.

A constelação familiar possui uma abordagem sistêmico-fenomenológica, que contribui para compreensão dos elementos geradores dos conflitos. Esse método permite acessar o que está oculto, as forças que atuam no sistema e as causas primordiais dos conflitos. Sendo assim, o método possibilita que as partes tomem consciência dos emaranhados do sistema, oportunizando a prestação jurisdicional satisfativa, o restabelecimento do diálogo, a maior compreensão dos desequilíbrios, a harmonia nos relacionamentos, o reconhecimento de papéis e, até mesmo, a pacificação do conflito.

As constantes divulgações de índices extremamente positivos relacionados à aplicação da constelação familiar como meio alternativo de solução de conflitos, pelo Conselho Nacional de Justiça, têm elevado o entusiasmo e ajudado a disseminar cursos, palestras e especializações sobre o assunto. Porém, a técnica começou a ser utilizada há pouco tempo e necessita de estudos acadêmicos mais aprofundados para a obtenção de dados concretos e precisos sobre sua eficácia. Até o momento, não há estatística que comprove a efetividade do método hellingeriano para dirimir conflitos judiciais

\footnotetext{
${ }^{39}$ CURY, Cesar. Entrevista do desembargador do TJ/RJ cedida ao Fantástico em 14/05/2017. Disponível em: <https://goo.gl/K2ww44>. Acessado em: 30/01/2018.
} 
No entanto, a constelação familiar é um instrumento que possui potencial para promover a humanização do Direito, podendo aproximar a prestação judicial do ideário de justiça, desde que seja aplicada por pessoal devidamente capacitado, com ponderação e cautela, até porque essa técnica ainda é desconhecida por boa parte da comunidade jurídica.

\section{REFERÊNCIAS BIBLIOGRÁFICAS}

BRAGA, Ana Lucia de Abreu. Psicopedagogia e Constelação familiar: um estudo de caso. Revista Psicopedagogia: Ribeirão Preto, 2009; 26 (80): p. 274 - 285. Disponível em:

<https://goo.gl/JiJ12d >. Acessado em: 25/01/2018.

BRASIL. Conselho Nacional de Justiça. Resolução no 125, de 29 de novembro de 2010. Brasília, 2010. Disponível em: 〈https://goo.gl/sL9Tbp〉. Acessado em: 26/08/17.

CALAMANDREI, Piero. Eles, os juízes, vistos por um advogado. São Paulo: Martins Fontes, 1 ed., $1995,397 \mathrm{p}$.

CARDOSO, Hélio Apoliano. Direito de Família à Luz da Constelação Familiar e do Direito Sistêmico. Revista Síntese de Direito de Família. São Paulo, v. 17, nº 97, p. 75-78, ago/set 2016. Disponível em: 〈https://goo.gl/2EWyJm>. Acessado em: 24/08/17.

CARMO, Maria Scarlet do. Uma Breve Apresentação sobre a Constelação Sistêmica Fenomenológica. Editora Atlas, 2015, 1 ed., 262 p.

CÉSPEDES, Adele Speck Rendón. A Constelação Familiar aplicada ao Direito Brasileiro a partir da Lei de Mediação. TCC (graduação) - Universidade Federal de Santa Catarina. Centro de Ciências Jurídicas. Julho de 2017. p. 58. Disponível em: 〈https://goo.gl/uzNxb1〉. Acessado em: $26 / 08 / 17$

CHIQUETTI, Taciana; CRUZ, Carlos Henrique Souza da. Psicologia Jurídica e Direito de Família: para além da perícia psicológica. Manaus: UEA Edições, 2017, 311 p.

DIAS, Cristiana Kaipper. As contribuições da teoria sistêmica de Bert Hellinger para a compreensão das relações humanas e resolução de conflitos. Revista Eletrônica da Fainor, Vitória da Conquista, v.7, n.1, p.3-17, jan./jun. 2014. Disponível em: 〈https://goo.gl/a6DPwA >. Acessado em: $24 / 01 / 18$.

DURKHEIM, Émile. Da divisão do trabalho social. Martins Fontes: São Paulo, 2010. 536 p.

FERREIRA, Cezar, Verônica A. da Motta. Família, separação e mediação: uma visão psicojurídica. São Paulo: Editora Método, 2004, 192 p.

FREUD, Sigmund. Psicologia das Massas e Análise do Eu e outros textos. Obras Completas Companhia das Letras - (1920-1923). Vol. 15. São Paulo: Companhia das Letras, 2011. 352 p.

FURTADO, Odair. In Psicologia sócio-histórica: uma perspectiva crítica em psicologia. Ana Mercês Bahia Bock, Maria da Graça Marchina Gonçalves, Odair Furtado (orgs.). São Paulo : Cortez, 2007, 3 ed., 224 p. 
HELLINGER, Bert. A paz começa na alma. Patos de Minas: Atman, 2003, 1 ed. 214 p.

A simetria oculta do amor: por que o amor faz os relacionamentos darem certo. São Paulo: Cultrix, 1998, 6 ed. 320 p.

Conflito e Paz: uma resposta. São Paulo: Cultrix, 2005, 1 ed.,152 p. Constelações familiares: o reconhecimento das ordens do amor. São Paulo: Cultrix;

2004, 4 ed. 160 p.

O amor do espírito na Hellinger Sciencia. Minas Gerais: Atman; 2009, 1 ed., 211 p.

Ordens do Amor: um guia para o trabalho com constelações familiares. São Paulo: Cultrix, 2007, 4 ed., 424 p.

LACERDA, Sttela Maris Nerone. Direito sistêmico e direitos humanos: a aplicação das constelações familiars para tratamento dos conflitos judiciais. In: II Simpósio Internacional Interdisciplinar em Ciências Sociais Aplicadas. Anais. Ponta Grossa: UEPG, 2017. Disponível em: <https://goo.gl/WBJsMD>. Acessado em: 30/01/2018.

LANKE, Fabiana, LOPES, Juliana, GALVÃO, Fabíola. Constelação familiar para autocomposição de conflitos: resultados preliminares do projeto-piloto da $1^{\mathrm{a}}$ Vara de Família da Leopoldina (TJRJ). Práxis: Ação Sistêmica. Disponível em: 〈https://goo.gl/LdSvQF>. Acessado em: 25/10/2017.

LUCACHINSKIL, Camila; LIPPMANN, Márcia. Constelações sistêmicas como técnica de resolução de conflitos familiares. Anais do III Congresso Catarinense de Direito Processual Civil. Univali - Campus Itajaí. Disponível em: <https://goo.gl/G75enq>. Acessado em: 30/01/2018.

ROSA. Amilton Plácido da. Direito sistêmico: a justiça curativa, de soluções profundas e duradouras. In: Revista MP Especial, ano 2, ed. 11, janeiro de 2014, Ministério Público do Mato Grosso do Sul, p. 50-57. Disponível em: 〈https://goo.gl/8ueTgK>. Acessado em: 30/01/2018.

SCHNEIDER, Jakob Robert. A prática das constelações familiares. Patos de Minas: Atman, 2007, 1 ed., $216 \mathrm{p}$.

SEVERI, Fabiana Cristina. O gênero da justiça e a problemática da efetivação dos direitos humanos das mulheres. Revista Direito e Práxis, v. 7, p. 80-115, 2016. Disponível em: <https://goo.gl/fMWhTh>. Acessado em: 25/10/2017.

STORCH, Sami. Direito sistêmico: a resolução de conflitos por meio da abordagem sistêmica fenomenológica das constelações familiares. Revista Entre aspas: revista da Unicorp / Tribunal de Justiça do Estado da Bahia - ano.1, n.1, (abr.2011) - Salvador: Universidade Corporativa do TJBA, 2011- Catalogação do volume 5, publicado em Julho de 2016. p. 305 - 316.

THEODORO JÚNIOR, Humberto. Curso de Direito Processual Civil - Teoria geral do direito processual civil, processo de conhecimento e procedimento comum. vol 1. 58. ed. rev., atual. e ampl. - Rio de Janeiro: Forense, 2017, 1540 p.

VASCONCELOS, Carlos Eduardo de. Mediação de Conflitos e Práticas Restaurativas. 4. ed. São Paulo: Método, 2016, 1 ed. 206 p.

WATANABE, Kazuo. Política judiciária nacional de tratamento adequado dos conflitos de interesses: utilização dos meios de resolução de controvérsias. In: MENDES, Aluísio Gonçalves de 
Castro; WAMBIER, Teresa Arruda Alvim (org.). O processo em perspectiva: jornadas brasileiras de direito processual. São Paulo: RT, 2013, 380 p. 